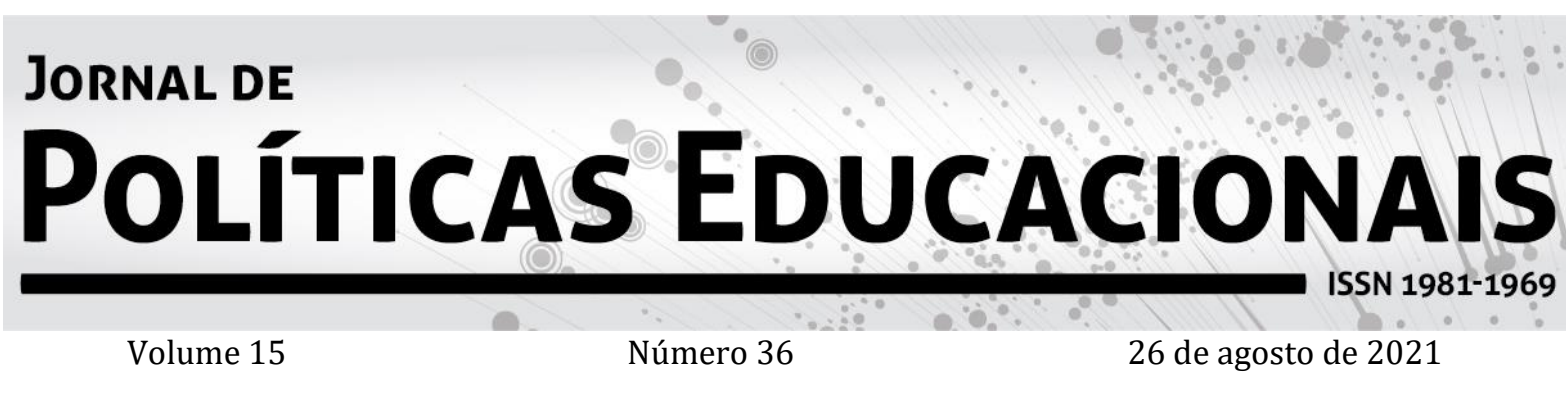

\title{
Neoliberalismo e Neoconservadorismo nas políticas educacionais para a formação da juventude brasileira
}

\section{Neoliberalism and Neoconservatism in the educational policies that aim the brazilian youth development}

\section{Neoliberalismo y Neoconservadurismo en políticas educativas para la formación de la juventud brasileña}

\author{
Vera Maria Vidal Peronil \\ Maria Raquel Caetano ${ }^{2}$ \\ Paula de Lima Valim ${ }^{3}$
}

Citação: PERONI, V. M.V; CAETANO, M.R; VALIM, P.L. Neoliberalismo e Neoconservadorismo nas políticas educacionais para a formação da juventude brasileira. Jornal de Políticas Educacionais. V. 15, n. 36. Agosto de 2021.

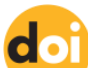

http://10.5380/ipe.v15i0.82294

Resumo: 0 objetivo do artigo é analisar as implicações dos projetos neoliberal e neoconservador na formação da juventude brasileira, que atuam disputando o conteúdo da educação, especialmente na etapa do Ensino Médio como parte do movimento de correlação de forças que ocorre na sociedade pela disputa por projetos societários e de educação. 0 artigo traz argumentos sobre as particularidades do neoliberalismo (pós-crise de 2008) e suas relações com o neoconservadorismo, que redefinem as fronteiras entre o público e o privado. Analisamos a proposta neoliberal de educação para o empreendedorismo e as propostas neoconservadoras do Escola sem Partido, militarização das escolas e homeschooling, como formas de materialização de seu projeto societário nas políticas de educação básica pública no Brasil, definindo seu conteúdo, com implicações para a construção de uma sociedade democrática e para a formação da juventude.

Palavras-chave: Ensino Médio, política educacional, neoliberalismo, neoconservadorismo, juventude.

\footnotetext{
${ }^{1}$ Doutora em História e Filosofia da Educação. UFRGS. Porto Alegre, RS, Brasil. https://orcid.org/00000001-6543-8431. E-mail: veraperoni@gmail.com

2 Doutora em Educação. IFSUL - Campus Sapucaia do Sul, BR. https://orcid.org/0000-0001-6973-908X. Email: caetanoraquel2013@gmail.com

${ }^{3}$ Mestre em Educação. Rede Municipal de Ensino de Porto Alegre, RS, Brasil. http://orcid.org/0000-00021798-7476. E-mail: paulavdelima@hotmail.com
} 


\section{JORNAL DE Políticas EducacionaIS \\ ISSN 1981-1969}

Abstract: The goal of this essay is to analyse the implications of the neoliberalism and neoconservatism which compete for the education content with projects that aim the development of the brazilian youth, specially during the high school as part of a strength correlation movement that takes place in the dispute for the corporate projects related to education. The essay brings arguments about the particularities of neoliberalism (after 2008 crisis) and the relationship with neoconservatism which redesign the boundaries between the public and the private. We analyse the neoliberal purpose for entrepreneurship education and the neoconservatism purposes of the movement "Escola sem Partido" (School without Party) such as militarisation of schools and homeschooling, as ways to materialize the corporate project in the basic public education policies in Brazil which intend to define the content and bring up implications to the development of a democratic society and to the youth development.

Keywords: High School, educational policies, neoliberalism, neoconservatism, youth.

Resumen: El objetivo del artículo es analizar las implicaciones de los proyectos neoliberales y neoconservadores en la formación de la juventud brasileña, que actúan en la disputa del contenido de la educación, especialmente en la etapa de Enseñanza Secundaria como parte del movimiento de correlación de fuerzas que ocurre en la sociedad por la disputa por proyectos societarios y educativos. El artículo apunta argumentos sobre las particularidades del neoliberalismo (postcrisis de 2008) y sus relaciones con el neoconservadurismo, que redefinen los límites entre lo público y lo privado. Analizamos la propuesta neoliberal de educación para el emprendimiento y las propuestas neoconservadoras de Escola sem Partido, militarización de las escuelas y educación en homeschooling, como formas de materializar su proyecto societario en las políticas públicas de educación básica en Brasil, definiendo su contenido, con implicaciones para la construcción de una sociedad democrática y para la formación de la juventud.

Palavras Clabe: Enseñanza Secundaria, política educativa, neoliberalismo, neoconservadurismo, juventud.

\section{Introdução}

0 texto tem como base as pesquisas realizadas pelo Grupo de Pesquisa Relações entre o Público e o Privado em Educação (GPRPPE) ${ }^{4}$, que estuda a relação entre o público e o privado na educação ${ }^{5}$, entendida como projetos societários em disputa, que ocorrem em um processo de correlação de forças atravessando Estado e sociedade civil. Neste período particular 6 do capitalismo, analisando o contexto nacional, verificamos forte influência de forças sociais, representadas por sujeitos individuais e coletivos (THOMPSON, 1981), que defendem projetos com interesses vinculados aos ideários neoliberal e neoconservador, em uma perspectiva de classe. Estes sujeitos atuam disputando a pauta educativa e sua materialização, com profundas implicações para a construção de uma sociedade democrática (PERONI, 2020), sendo a democracia

\footnotetext{
${ }^{4}$ No site estão reunidas as publicações e relatórios de pesquisa do grupo: https://www.ufrgs.br/gprppe/.

${ }^{5}$ Relação entre o público e privado, pois vivemos processos de democratização e fortalecimento do público ao mesmo tempo em que avançou o projeto de privatização e mercantilização.

${ }^{6}$ Particular entendido como mediação na análise (LUKÁCS, 1978).
} 


\section{JORNAL DE} Políticas EducacionaIS

ISSN 1981-1969

entendida como "a materialização de direitos em políticas coletivamente construídas na autocrítica da prática social" (PERONI, 2013, p. 1021).

Entendemos que o privado não pode ser tratado como uma abstração, mas como um processo materializado pela ação de sujeitos, por isso em nossas pesquisas analisamos quem são os sujeitos, quais são as suas relações e qual é o conteúdo de suas propostas (PERONI, 2020). Neste artigo o objetivo é analisar as implicações dos projetos educativos neoliberal e neoconservador na formação da juventude brasileira, que atuam disputando o conteúdo da educação na perspectiva de restauração do poder de classe, buscando avançar na construção de um projeto societário com uma nova proposta de socialização.

Rikowski (2017) apresenta a discussão da privatização na educação e da educação. Na primeira forma de privatização, a educação é um grande mercado e o setor privado disputa pelo fundo público com vistas à obteção de lucro, na perspectiva da capitalização da educação: trata-se, essencialmente, "do desenvolvimento capitalista na educação" (RIKOWSKI, 2017, p. 401). Já a privatização na educação trata da disputa pelo seu conteúdo em um processo que não envolve a propriedade, mas "a tomada de controle sobre a educação" (RIKOWSKI, 2017, p. 400). Nesta forma de privatização, a escola permanece pública, é o Estado que paga o professor e define parcerias ou compras de pacotes, mas a direção da educação e a definição do conteúdo educativo é repassada para o setor privado, bem como sua execução, uma vez que este passa a ser responsável pela formação de professores, por exemplo.

Estudamos parcerias do setor público com instituições privadas como Instituto Ayrton Senna (ADRIÃO; PERONI, 2011), Instituto Unibanco (CAETANO, 2018; CARVALHO, 2020) e Fundação Lemann (PERONI; OLIVEIRA, 2020), que atuam na definição do conteúdo das escolas, estabelecendo mecanismos de gestão para resultados e monitoramento. As parcerias que atuam na formação de professores, trazem aulas prontas e projetos padronizados e replicáveis, que possibilitam o controle do processo educativo, em um processo cada vez maior de alienação do trabalho docente. 0 professor recebe o material pronto, abstraindo sua condição de intelectual que produz o conhecimento, em um processo de controle e censura (PERONI, 2020). 


\section{JORNAL DE} Políticas EducacionaIS

ISSN 1981-1969

A privatização na educação é, portanto, uma forma de disputar e controlar seu conteúdo, em uma perspectiva de restauração do poder de classe. Significa que dizer que os projetos de privatização são, antes de tudo, projetos de classe, que objetivam difundir influências ideológicas por meio diferentes instituições que constituem a sociedade civil, incluídas a escola e universidade, em um processo de construção ativa do consentimento político:

Aquilo que Gramsci denomina "senso comum" (definido como "o sentido sustentado em comum") tipicamente fundamenta o consentimento. 0 senso comum é construído com base em práticas de longa data de socialização cultural que costumam fincar profundas raízes em tradições nacionais ou regionais (HARVEY, 2014, p. 49).

A restauração do poder de classe depende da incorporação pelo senso comum de um determinado aparato conceitual que o legitime, a tal ponto que seja naturalizado e livre de questionamento (HARVEY, 2014). Em contextos em que a hegemonia das classes dominantes se encontra ameaçada, diferentes estratégias são elaboradas para restaurar o poder de classe, como "no recente caso brasileiro, [que] se viu ameaçado por um período de avanços nas questões sociais" (PERONI; LIMA, 2020, p. 7). Entre as estratégias, destacam-se, neste momento, o neoliberalismo e o neoconservadorismo, com implicações nas relações entre o público e o privado e no processo de democratização da educação.

Desse modo, entendemos a relação entre o público e o privado nas políticas educacionais como parte da materialização das correlações de forças que ocorrem na sociedade em um período particular. Já tratamos do tema da influência neoliberal e neoconservadora na política educacional, analisando sua materialização por meio da Base Nacional Comum Curricular e do Escola sem Partido (PERONI; LIMA; CAETANO, 2017). Infelizmente, passados quatro anos, vivenciamos o aprofundamento destes processos e por isso voltamos ao tema, demonstrando a continuidade de algumas propostas e o surgimento de outras formas de materialização do projeto educativo neoliberal e neoconservador.

Na primeira parte do texto trazemos alguns elementos para o debate acerca das particularidades do neoliberalismo pós-crise de 2008, com as reformas de segunda 


\section{JORNAL DE} Políticas EducacionaIS

ISSN 1981-1969

geração do Consenso de Washington, e suas relações com o neoconservadorismo, que redefinem as fronteiras entre o público e o privado e se efetivam por meio das disputas pelo conteúdo das políticas de educação básica no Brasil. Na segunda parte, analisamos de que forma o projeto educativo neoliberal se materializa na política educacional para a juventude associado ao empreendedorismo e à lógica mercantil. Em seguida, apresentamos algumas propostas para a educação que materializam o projeto educativo neoconservador.

\section{Neoliberalismo, neoconservadorismo e as exigências do capital}

O neoliberalismo apresenta-se com particularidades no contexto pós-crise de 2008, pois, segundo Puello-Socarrás (2008), "el neoliberalismo hoy por hoy lejos de agotarse se reedita. Presenciamos alguna suerte de reactualización que se prolonga en el tiempo y en el espacio, tanto a nivel global como local" (PUELLO-SOCARRÁS, 2008, p. 81). Neste contexto, de acordo com o autor, o Estado redefine seu papel, de Estado mínimo para Estado empresarial, a partir das reformas de segunda geração do Consenso de Washington, "las cuales dirigen su interés en torno a las reformas políticas e institucionales han estado dominadas por el tema de la reforma estatal y sus implicaciones" (PUELLO-SOCARRÁS, 2008, p. 107).

O governo asume características gerenciais, configurando o que o autor chama de governo empresarial, que tem como proposta o cliente de serviços a ser buscado no mercado, já que o governo evita a prestação direta de serviços, fugindo do que a teoria neoliberal critica como monopólio do Estado na execução de políticas: "El gobierno empresarial limitaría su rol a la regulación pública, evitando la prestación directa de los servicios sociales, manteniendo niveles óptimos de competencia e impidiendo al máximo las situaciones monopólicas y las interferencias en el mercado (PUELLO-SOCARRÁS, 2008, p. 113). O gerencialismo é parte do diagnostico neoliberal de que a crise está no Estado e o mercado é parâmetro de qualidade. 0 que permanece no Estado tem o parâmetro do mercado, como é o caso a nova gestão pública e os processos de 


\section{JORNAL DE} Políticas EducacionaIS

ISSN 1981-1969

privatização na educação. A disputa entre gestão gerencial e democrática, é muito mais que uma discussão só gerencial ou não gerencial, é parte de projetos muito mais amplos (PERONI; LIMA, 2020).

As transformações do neoliberalismo em sua nova versão no século XXI trazem como mudança o homem econômico em homem empresário/empreendedor, a partir da incorporação de novas bases teóricas. Segundo Puello-Socarrás (2008), o homem econômico segue reforçando o individualismo próprio do neoliberalismo e o aprofunda, agora com uma nova concepção, em que "el hombre empresario/emprendedor es entonces uma exigencia epistemológica - ideológica y política - que genera una comprensión mucho más funcional/ajustada sobre la fase del capitalismo avanzado" (PUELLO-SOCARRÁS, 2008, p. 85), sobretudo porque torna-se uma força do mercado, conduzindo à individualidade e não à coletividade.

0 neoconservadorismo tem sido também elemento importante para entendermos este período particular do capitalismo. Atribuindo à crise um caráter de crise moral, fruto do abandono de determinados valores tradicionais, os neoconservadores compartilham com os neoliberais o diagnóstico de que o culpado pela crise é o Estado, mas o fazem sob o argumento de que sua interferência na economia e na promoção de políticas sociais desestimula o trabalho, diminui a produtividade e toma "o lugar da família, da igreja e da comunidade, enfraquecendo esses laços, supostamente, naturais" (MOLL NETO, 2015, p. $55)$.

Além da responsabilização do Estado sobre a crise, neoliberalismo e neoconservadorismo compartilham a defesa do poder corporativo, da governança pela elite, da iniciativa privada, da restauração do poder de classe e da desconfiança da democracia (HARVEY, 2014). No entanto, existem diferenças, como a preocupação com a ordem social, em que o neoconservadorismo defende uma moralidade inflexível como cimento social, o que não é uma característica do neoliberalismo. Segundo Harvey (2014), a diminuição das políticas sociais, o aumento do desemprego, dos ajustes estruturais e a exacerbação da competitividade e do individualismo provocam o caos social e civilizatório, ao que o neoconservadorismo responde recorrendo ao punitivismo e ao 


\section{JORNAL DE Políticas Educacionals}

ISSN 1981-1969

fortalecimento da família tradicional. É a realidade que temos vivenciado no Brasil no contexto atual.

Após mapear as raízes do neoconservadorismo, Moll Neto (2010) explica-o como a conjunção de pressupostos do velho conservadorismo e do libertarianismo ${ }^{7}$. 0 autor ressalta que a questão principal de união entre os grupos era o individualismo, pois, para eles "nada justificava projetos estatais que interferissem na vida das pessoas e limitassem as liberdades, sobretudo a econômica" (MOLL NETO, 2010, p. 67).

A questão do individualismo se contrapõe à coletivização, que seria a proposta democrática de universalização de direitos, entendendo que as transformações se dão na esfera pessoal e não em termos societários (PERONI, 2020). A primazia do indivíduo em relação ao coletivo garante a não interferência do Estado nas escolhas parentais, de modo que as famílias - e somente elas - podem decidir sobre aspectos relativos à formação de seus filhos, sejam ideológicos, morais, políticos, etc; ao mesmo tempo em que permite, a partir da perspectiva dos valores da competição, empreendedorismo e mérito, cada indivíduo é responsabilizado por seu próprio sucesso ou fracasso, desconsiderando fatores e propriedades sistêmicas estruturais (HARVEY, 2014).

\section{Empreendedorismo e as Políticas de Educação Empreendedora nas redes públicas de ensino para o Ensino Médio}

As propostas de educação empreendedora foram produzidas no contexto da reestruturação produtiva do capital. Uma das estratégias de combate ao desemprego no Brasil e no mundo tem sido o incentivo à formação de empreendedores, especialmente para os jovens que aparecem como um dos principais alvos propostos pela lógica do capital. Essas propostas visavam e ainda visam solucionar, por meio de políticas e programas educacionais, problemas de ordem estrutural do capital. Assim como nas reformas educacionais, em que o discurso da competência e do desenvolvimento das

\footnotetext{
7 Os libertários reivindicam o Estado mínimo não só na economia, mas também sobre a vida pessoal (LACERDA, 2019, p. 54). 0 libertarianismo é associado ao ultraliberalismo, pois apresenta radicalização de posições referentes à liberdade em relação ao liberalismo clássico e o neoliberalismo (ROCHA, 2018).
} 


\section{JORNAL DE}

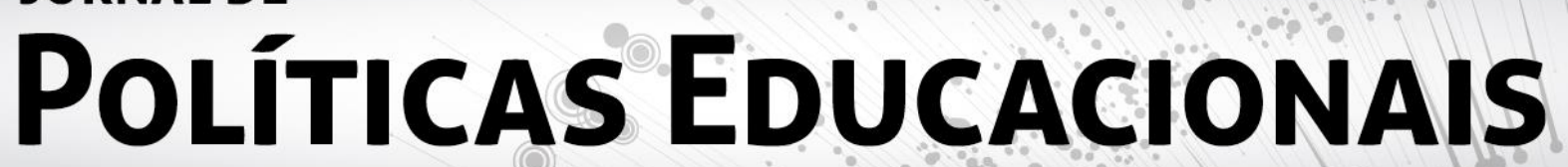

ISSN 1981-1969

capacidades empreendedoras dos cidadãos entraram nos textos das políticas educacionais.

O empreendedorismo passou a ser incentivado pelos organismos internacionais como solução para o desemprego especialmente na América Latina partindo das novas formulações sobre a reforma do Estado com base na lógica mercantil, do gerencialismo e das parcerias com o terceiro setor, redefiniu o conteúdo das políticas e o papel do setor público no atendimento das questões sociais. Essa lógica foi introduzida na educação pelos organismos internacionais como a Unesco, no Relatório Educação para o século XXI: "Educação um tesouro a descobrir", de Jaques Delors, adicionando, em 2002, um quinto pilar: "aprender a empreender" fundamentado no empreendedorismo, via reformas educacionais (CAETANO, 2020).

Neste contexto, o empreendedorismo tem representado uma estratégia ideológica que sustenta o projeto de sociedade defendido pelos grupos hegemônicos representantes do capital que legitimam o mercado como solução para os problemas sociais. Para tal intento, necessita de um projeto pedagógico para educar a juventude: a educação para o Empreendedorismo.

No Brasil, o empreendedorismo vem sendo inserido no currículo escolar com propostas da classe empresarial e instituições do terceiro setor, como a Reforma do Ensino Médio e a BNCC (PERONI; CAETANO; ARELARO, 2019), evidenciando as novas formas de organização do trabalho produtivo para qualificar em novas bases a juventude, com a justificativa de ser uma exigência para a educação do século XXI. Ao mesmo tempo, busca influenciar e direcionar qual o conteúdo necessário para essa formação em um projeto de classe cujo foco passa a ser a educação pública, responsável por grande parte das matrículas no ensino médio regular.

Em uma sociedade de classes, em que os empregos não são para todos, o empreendedorismo integra o discurso ideológico e meritocrático utilizado para levar as pessoas a aceitarem as relações sociais vigentes sem questioná-las, pois "as ideias da classe dominante são, em cada época, as ideias dominantes" (MARX; ENGELS, 2007, p. 72). 


\section{JORNAL DE} Políticas EducacionaIS

É nesse contexto que a classe dominante precisa operar seu projeto na formação da juventude pois essa,

[...] é uma proposta organicamente articulada ao projeto histórico do capital. Argumenta-se que essa orientação, que promete realizar o sonho do sucesso pessoal e profissional, opera no sentido de naturalizar a condição de protagonista do jovem, único responsável por sua sobrevivência e pelo desenvolvimento econômico da coletividade a que pertence, revelando ser este um discurso pragmático e ideológico que reforça o individualismo característico da racionalidade neoliberal, o que permite apresentar as formulações que orbitam em torno da formação dos trabalhadores/empreendedores como ideologia (COAN, 2013, p. 12).

A proposta do empreendedorismo procura estabelecer-se como eixo da educação, atrelando-o a geração de alternativas para o desemprego de modo a assegurar que, mesmo em tempos de crise, se mantenha a produção coletiva de riquezas, preservando a apropriação privada e o individualismo. Apoiado por essas formulações e pelas reformas educacionais, a classe hegemônica empresarial vem buscando legitimar seu projeto para a educação pública.

É no contexto da Reforma do Ensino Médio que estados têm elaborado legislações incluindo o ensino do empreendedorismo nos currículos escolares. Proliferam diferentes propostas ou soluções educacionais vindas de instituições privadas e do terceiro setor para a educação pública brasileira. Uma delas é a proposta de Educação Empreendedora do SEBRAE $^{8}$ que tem sugerido às secretarias de educação públicas seus programas, indicando-os como uma solução para a implantação da Base Nacional Comum Curricular (BNCC) e oferecendo seus serviços/consultorias nessas elaborações (CAETANO, 2020). Outrossim, vários estados brasileiros instituíram legislações com políticas ou programas de empreendedorismo nas redes estaduais de ensino. Como exemplos, mapeamos um

\footnotetext{
8 O SEBRAE-Serviço Brasileiro de Apoio às micro e pequenas empresas é uma entidade privada que promove a competitividade e o desenvolvimento sustentável dos empreendimentos de microempresas atuando com foco no empreendedorismo por meio de parcerias com setores público e privado. No RS, seu conselho é composto por instituições da base empresarial (SEBRAE, 2021).
} 


\section{JORNAL DE} Políticas EducacionaIS

ISSN 1981-1969

estado de cada região brasileira que já instituiu políticas e diretrizes para implantar a educação empreendedora nos currículos das escolas públicas, apresentados no quadro:

QUADRO 1 - Estados que instituíram legislação sobre Empreendedorismo no currículo

\begin{tabular}{|c|c|c|}
\hline UF & LEI & RESUMO \\
\hline RS & $\begin{array}{l}\text { Lei № } 15.410 \text { de } 19 \text { de } \\
\text { dezembro de } 2019\end{array}$ & $\begin{array}{l}\text { Institui a Política Estadual de Educação Empreendedora, a } \\
\text { ser desenvolvida no âmbito das escolas técnicas e das } \\
\text { escolas de nível médio do Estado do Rio Grande do Sul. }\end{array}$ \\
\hline SP & $\begin{array}{l}\text { Lei № } 15.693 \text {, de } 03 \text { de } \\
\text { março de } 2015\end{array}$ & $\begin{array}{l}\text { Cria o Plano Estadual de Educação Empreendedora, para } \\
\text { inserção do empreendedorismo nas escolas de ensino } \\
\text { médio e escolas técnicas. }\end{array}$ \\
\hline MT & $\begin{array}{l}\text { Lei № } 11.233 \text { de } 19 \text { de } \\
\text { outubro de } 2020\end{array}$ & $\begin{array}{l}\text { Institui diretriz para o estímulo ao empreendedorismo } \\
\text { para alunos do ensino médio de rede de educação pública } \\
\text { do estado do Mato Grosso. }\end{array}$ \\
\hline $\mathrm{CE}$ & $\begin{array}{l}\text { Lei №17.334, } 10 \text { de } \\
\text { novembro de } 2020\end{array}$ & $\begin{array}{l}\text { Institui o programa estadual "Educação Empreendedora e } \\
\text { Inovadora" no estado do Ceará. }\end{array}$ \\
\hline $\mathbf{R R}$ & $\begin{array}{l}\text { Lei Complementar № } 274 \\
\text { de } 30 \text { de outubro de } 2018 \\
\text { Projeto de Lei } n^{\circ} 015 / 2020\end{array}$ & $\begin{array}{l}\text { Busca introduzir conceitos básicos de educação financeira } \\
\text { aos alunos da Rede Básica de Ensino. }\end{array}$ \\
\hline
\end{tabular}

Fonte: Portal eletrônico das respectivas Assembleias Legislativas. Elaboração das autoras.

Conforme dados do quadro, as legislações instituídas são atuais, pós Reforma do EM e BNCC, exceto São Paulo, mas que também ganhou força no atual período. Nesses estados encontramos a atuação do SEBRAE que também é parceiro e apoiador do Consed ${ }^{9}$ e Undime ${ }^{10}$, auxiliando na elaboração (direção) de políticas ou na sua execução, através dos programas que oferecem às redes estaduais via parcerias na formação de professores, de estudantes e conjunto de materiais didáticos tendo o empreendedorismo como tema principal, mas inclui educação financeira, ensino híbrido, metodologias ativas, protagonismo juvenil e competências socioemocionais: otimismo, flexibilidade, resiliência, empatia, responsabilidade, persistência, iniciativa, que também são consideradas nesses programas, características empreendedoras e ao mesmo tempo, referem-se ao conteúdo da BNCC.

\footnotetext{
${ }^{9}$ No site do Consed, o SEBRAE aparece como parceiro em conjunto com outras instituições (CONSELHO NACIONAL DE SECRETÁRIOS DE EDUCAÇÃO, 2021).

${ }^{10}$ Undime (União Nacional dos Dirigentes Municipais de Educação). Ver Diário do Amapá (2020).
} 


\section{JORNAL DE} Políticas EducacionaIS

ISSN 1981-1969

$\mathrm{Na}$ justificativa dos Projetos de Lei encontramos que os programas poderão ser realizados com outras instituições, como é o caso do Projeto de Lei da Paraíba: "podendo tal ser realizada em conjunto com instituições como Sebrae, Fiec, Fecomércio, CDL, entre outras, com o intuito de fomentar o empreendedorismo cearense para os jovens" (PARAÍBA, 2020). Já no Rio Grande do Sul, a justificativa são as iniciativas já realizadas em municípios com o Sebrae, Senar e o Sicredi (RIO GRANDE DO SUL, 2019). Convém lembrar que a atual Política Estadual de Educação Empreendedora prevê a inclusão de conteúdos e atividades que promovam a cultura empreendedora nos projetos pedagógicos e planos escolares, para a realização de práticas empreendedoras no processo de ensino e aprendizagem (RIO GRANDE DO SUL, 2019), alterando o conteúdo da escola e os princípios da gestão democrática. Embora a legislação seja estatal e a escola permaneça pública, a execução das políticas poderá ser realizada por entes privados, ou seja, é o Estado Empreendedor em ação, facilitador de negócios, terceirando a execução da educação em programas caracterizados pelo discurso da inovação, tecnologia, modernização, empreendedorismo, competências socioemocionais em detrimento da formação humana integral e omnilateral, em um novo projeto educacional e social.

Nesse cenário, a classe dominante precisa ocultar os antagonismos presentes na sociedade, para isso apresenta suas aspirações coletivas e seus projetos como interesse comum. As ideias dominantes são "a expressão ideal das relações materiais dominantes, são as relações materiais apreendidas como ideias, portanto, são a expressão das relações que fazem de uma classe a classe dominante, são as ideias de sua dominação" (MARX; ENGELS, 2007, p. 47).

A educação para o empreendedorismo cumpre o papel destinado à formação da juventude de influenciar seus modos de pensar, agir e sentir, para que o jovem atue como protagonista na produção e reprodução de valores do mercado para a construção dessa nova sociedade.

Para implantar os projetos e programas, o Estado se vale das parcerias públicoprivadas e/ou contratos de gestão com o terceiro setor e/ou instituições privadas, uma forma pública não estatal de intervenção institucional, que possui muitas implicações no processo 


\section{JORNAL DE}

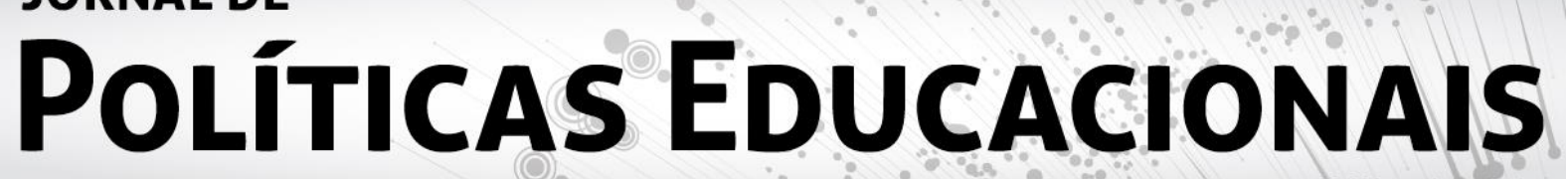

ISSN 1981-1969

educacional. É o caso do SEBRAE ao executar o Programa Educação Empreendedora que se apresenta como detentor das soluções educacionais para a escola pública, com o apoio do poder público. Os programas oferecidos para a educação pública visam modificar substancialmente o conteúdo ofertado nas escolas públicas estaduais. Além disso, a educação para o empreendedorismo, como política, esvazia o conteúdo educacional democrático. Essas políticas revelam a face economicista, conservadora e estratégica nas lutas em prol de uma visão de mundo dominante, pois alia meritocracia, competitividade e individualismo na contramão na construção de um projeto mais democrático, igualitário e de valorização da diversidade.

\section{Políticas neoconservadoras para a educação}

Para construir a nova sociedade para o século XXI, conforme abordamos, setores neoconservadores buscam construir, como fazem os neoliberais, projetos pedagógicos/educativos em consonância com os valores e as perspectivas de seu projeto societário, buscando educar a juventude a partir de um determinado conjunto de ideias: "Nenhum modo de pensamento se torna dominante sem propor um aparato conceitual que mobilize nossas sensações e nossos instintos, nossos valores e nossos desejos, assim como as possibilidades inerentes ao mundo social que habitamos" (HARVEY, 2014, p. 15).

Assim, constrói-se um discurso ideológico que se propõe a criar as condições que favoreçam a materialização de seu projeto societário. Diferentes propostas que atualmente integram o debate público educacional, especialmente a partir das eleições de 2018 e no contexto do governo de Jair Bolsonaro, mostram-se alinhadas a esta perspectiva, centradas na disputa pelo conteúdo da educação pública. Projetos de lei de natureza do Escola sem Partido (ESP), que promovem a censura e interdição do trabalho docente em relação ao conteúdo educativo; programas que promovem a militarização de escolas públicas; e medidas que visam fomentar e regulamentar a prática de Ensino Domiciliar e contestam a frequência à escola são alguns exemplos de propostas vinculadas às perspectivas neoconservadoras que se apresentam como estratégia 


\section{JORNAL DE} Políticas EducacionaIS

ISSN 1981-1969

ideológica de restauração do poder de classe. As três propostas, cabe destacar, já existem há quase de duas décadas no Brasil e se apresentem em diferentes etapas no processo de materialização.

Os projetos que buscam combater a "doutrinação política e ideológica" e a "ideologia de gênero" em sala de aula são fruto da articulação neoconservadora em torno do Movimento Escola sem Partido, criado ainda no ano de 2004 (LIMA, 2017; PERONI; CAETANO; LIMA, 2017; LIMA, 2018). Desde lá, mais de uma centena de projetos de lei foram propostos em diferentes casas legislativa por todo o país. Estes projetos se configuram como mecanismos de controle dos conteúdos escolares e interdição dos discursos e práticas dos professores, na tentativa de impedir que transitem pela escola determinadas visões de mundo:

Ao definir os conteúdos, conceitos, metodologias e ações que os docentes e discentes devem desenvolver [...], difundem-se visões de mundo, conhecimentos, valores e perspecivas que representam os interesses de determinados grupos econômicos, em detrimento da pluralidade que deve estar na base de toda prática educativa (GIROTTO, 2016, p. 72).

O mesmo ocorre no processo de militarização das escolas, em que instituições públicas civis passam a contar com atuação de militares a partir de parcerias entre as Secretarias de Educação e Secretarias de Segurança. É uma prática que tem no ano de 2019 um marco de fortalecimento, a partir da criação do Programa Nacional da Escolas Cívico-Militares pelo governo de Jair Bolsonaro, prevendo a atuação de militares nas áreas educacional, didático-pedagógica e administrativa em mais de 200 instituições educativas até o ano de 2023 (BRASIL, 2021). A iniciativa inspirou ações como a do estado do Paraná que, em 2020, aprovou uma Lei que institui uma versão local do programa, intitulado "Programa de Colégios Cívico-Militares no Estado do Paraná" (PARANÁ, 2020). Para além do controle do conteúdo educativo e do trabalho docente, o processo de militarização das escolas opera em uma perspectiva mais ampla de controle social, especialmente da juventude, a partir do qual "muitos governantes têm fomentado políticas públicas — sutis 


\section{JORNAL DE} Políticas EducacionaIS

ISSN 1981-1969

e legitimadas — que caminham na direção da submissão dos cidadãos e contribuem para a manutenção do poder e do controle sobre eles" (ALVES; FERREIRA, 2020, p. 4).

Os dois projetos têm em comum a tentativa de padronização de atitudes, comportamentos e modos de pensar, impedindo a expressão da diversidade e, consequentemente, o exercício democrático de convivência com diferentes visões de mundo e perspectivas políticas e ideológicas. Também ferem elementos fundamentais do princípio constitucional da gestão democrática da escola, por um lado porque impedem a expressão de determinadas ideias e posições políticas/ideológicas sobre o mundo e a sociedade; por outro lado porque efetivamente retrocedem em mecanismos já estabelecidos na legislação brasileira, como a organização autônoma dos estudantes em entidades representativas ${ }^{11}$ e a participação da comunidade escolar no processo de eleição de diretores ${ }^{12}$.

Assim, as propostas objetivam eliminar da escola os processos democráticos, o pensamento crítico e "práticas que se propõem transgressoras, que questionam o pensamento hegemônico e procuram construir alternativas à lógica do capital" (PERONI; CAETANO; LIMA, 2017, p. 423), para promover uma educação que dê conta de produzir conformidades e consensos (MÉSZÀROS, 2008) que favoreçam os interesses do sistema capitalista, ao mesmo tempo em que se busca impor uma determinada moralidade e impedir a subversão aos valores morais tradicionais.

Trata-se, essencialmente, de tentativas de transformar o espaço escolar em um espaço compatível com o projeto neoconservador, que o legitime e o fortaleça. Em paralelo à disputa pelo controle das escolas públicas que se dá por meio de projetos como

\footnotetext{
${ }^{11}$ A exemplo do Projeto de Lei no 246/2019, que institui o Programa Escola sem Partido e "explicita a proibição de atividades político-partidárias por parte dos grêmios estudantis" (BRASIL, 2019); e o Regulamento das Escolas Cívico-Militares que prevê que as escolas cívico-militares poderão "congregar os alunos em grêmios, clubes, núcleos e grupos que reflitam interesses comuns de seus integrantes, desde que estejam autorizados pelo Diretor, alinhados às orientações didático-pedagógicas das Ecim e sob a supervisão de um orientador civil ou militar" (BRASIL, 2020), embora a Lei no 7.398/1985 assegure a autonomia das entidades e dos estudantes em sua organização.

${ }^{12}$ A exemplo da Lei no 20.338/2020, que estabelece que "à seleção do Diretor-Geral de Instituição de Ensino, do Diretor-Auxiliar e do Diretor Cívico-Militar não se aplica o processo de consulta de que trata a Lei no 18.590, de 13 de outubro de 2015" (PARANÁ, 2020).
} 


\section{JORNAL DE} Políticas EducacionaIS

ISSN 1981-1969

o Escola sem Partido e a militarização, os neoconservadores apresentam uma terceira estratégia: "assegurar o direito ao homeschooling, onde estes possam ensinar seus próprios currículos" (CECCHETTI; TEDESCO, 2020, p. 13).

A proposta de regulamentar o ensino domiciliar atende integralmente ao caráter individualista do projeto neoconservador. Por meio dela, as famílias restrigem o convívio dos filhos no espaço escolar, impedindo que se deparem com visões de mundo diversas, negando a elas a oportunidade de produção autônoma de suas próprias ideias (MIGUEL, 2016). Trata-se de uma estratégia para que a família dentenha "controle sobre os temas postos em discussões, sobre o currículo, sobre as diferentes posições axiológicas, sobre os valores e as visões de mundo que convivem e, não raro, entram em conflito" (PICOLI, 2020, p. 4). Além disso,

[...] a defesa de Educação Domiciliar se fundamenta em preceitos que enaltecem o poder dos pais não apenas sobre a aprendizagem, mas sobre a vida de seus filhos, visto que direcionam os processos de ensino conforme determinada visão de sociedade, do conhecimento produzido, do modelo familiar e até mesmo da religião, impedindo que crianças e adolescentes convivam com a diversidade social, cultural e de crenças. Tais práticas de ensino podem influenciar a formação de pessoas intolerantes para a convivência em sociedade (WENDLER; FLACH, 2020, p. 3-4).

As propostas congregam alguns pontos que representam os fundamentos do neoconservadorismo apontados por Lacerda (2019), entre os quais destacam-se: o combate ao pensamento de esquerda, notadamente o "marxismo cultural", atualizando as bases do anticomunismo; a defesa da família patriarcal e a oposição às reivindicações feministas e LGBT em geral, sintetizadas na figura da "ideologia de gênero"; o idealismo punitivo, ou neoconservadorismo penal, que diz respeito ao endurecimento da legislação punitiva como instrumento de controle social. Os dois primeiros pontos se materializam com mais evidência nas propostas do Escola sem Partido e do Ensino Domiciliar, este último ponto se relaciona mais com o processo de militarização das escolas, que prioriza escolas em contextos de vulnerabilidade social. Desse modo, "relaciona indevidamente pobreza e violência e demonstra uma forma preconceituosa com relação às pessoas que 


\section{JORNAL DE Políticas Educacionals}

ISSN 1981-1969

vivem em situação de vulnerabilidade social, sobretudo os jovens"13, ao mesmo tempo em que desconsidera fatores e propriedades sistêmicas estruturais (HARVEY, 2014) que geram desigualdades sociais.

\section{Considerações finais}

Retomamos o objetivo do artigo de analisar as implicações dos projetos neoliberal e neoconservador na formação da juventude brasileira, que atuam disputando o conteúdo da educação, especialmente na etapa do Ensino Médio, buscando promover uma cultura de individualismo e valorização do privado em contraposição ao coletivo e público, destacamos que há uma naturalização das perdas vinculadas as propostas de juventude e Ensino Médio que estiveram em disputa nas políticas públicas no período anterior, como as propostas de educação para formação humana integral e do trabalho como princípio educativo, como Programa Ensino Médio Inovador e Fórum em defesa do Ensino Médio que ocorreram tanto nos projetos vinculados ao conteúdo da proposta das políticas vinculado ao EM como as propostas vinculadas as políticas de diversidade (ROSSI, 2016).

Ao disputar o conteúdo da formação da juventude na escola pública, o que no Brasil corresponde principalmente as camadas populares, os setores vinculados ao capital disputam um projeto societário, de restauração de classe, conforme analisamos no início deste artigo, que une neoliberalismo e neoconservadorismo com algumas propostas semelhantes e outras distintas. Ao longo do artigo demonstramos algumas formas de materialização das duas propostas e suas especificidades e semelhanças.

Como semelhanças entre as propostas apresentadas, verificamos as possibilidades de mudanças nas propostas de gestão democrática e no controle do conteúdo das escolas que participam dos programas via alteração nos currículos escolares e na gestão da escola. É preciso ressaltar que as propostas da formação de empreendedores, educação

\footnotetext{
${ }^{13}$ Trecho da justificariva que acompanha o Substitutivo Geral ao Projeto de Lei no 543/2020, que institui o programa "Educação democrática" na Rede Estadual de Ensino do Paraná, em substituição ao "Programa de Colégios Cívico-Militares", então em tramitação.
} 


\section{JORNAL DE}

\section{POLÍTICAS EDUCACIONAIS}

ISSN 1981-1969

domiciliar, militarização das escolas e competências socioemocionais são também formas de socializar as jovens gerações e controlar o conteúdo educativo e o trabalho docente.

Em ambas as propostas, o resultado fim é transformar estudante e professor em sujeitos empreendedores: o empreendedor de si, pois terá que se adaptar ao mundo do individualismo, da competição e da responsabilização, não apenas no que diz respeito ao processo produtivo, mas no sentido da responsabilização por sua condição de empregabilidade, em detrimento da perda dos direitos sociais e trabalhistas conquistados recentemente.

Assim, o currículo do Ensino Médio passa a ser um dos focos do interesse do capital, tanto via neoliberalismo, quanto neoconservadorismo, para a construção de um novo projeto societário com novas bases educacionais em que a solidariedade se torna concorrência: ao invés de objetivos comuns que beneficiam o público, cada um é levado a evidenciar sua própria condição, dificultando a construção de um projeto democrático e coletivo.

Enfim, destacamos a complementaridade entre neoconservadorismo e neoliberalismo em relação a preservação do sistema capitalista e, quando possível, seu fortalecimento, buscando restaurar condições para a acumulação ativa do capital. Neste sentido, a educação se constitui um terreno de disputas para a formação desta nova racionalidade, em que neoliberalismo e neoconservadorismo disputam a hegemonia utilizando, muitas vezes, os próprios mecanismos democráticos, de modo a criar determinados consensos por meio do convencimento, com uma natureza antidemocrática que conforma, segundo Laval e Dardot (2017), "un processo general de 'desdemocratización', que consiste em vaciar la democracia de su sustancia sin suprimirla formalmente" (LAVAL; DARDOT, 2017); sem abster-se, quando necessário, de utilizar algum grau de coerção (HARVEY, 2014), com estratégias autoritárias que trazem implicações para a democracia e a democratização da educação. 


\section{JORNAL DE Políticas Educacionals}

ISSN 1981-1969

\section{Referências}

ADRIÃO, T. M. F.; PERONI, V. M. V. Consequências da atuação do Instituto Ayrton Senna para a gestão da educação pública: observações sobre 10 estudos de caso. Práxis Educativa (Impresso), v. 6, p. 31-44, 2011.

ALVES, M. F.; FERREIRA, N. S. R. O processo de militarização de uma escola estadual pública em Goiás. Educação e Sociedade. vol. 41, p. 1-14. Campinas, 2020.

BRASIL. Câmara dos Deputados. Projeto de Lei no 246 de 2019. Institui o "Programa Escola sem Partido". Brasília, 2019.

BRASIL. Ministério Da Educação. Secretaria De Educação Básica. Manual das Escolas Cívico-Militares. Brasília, 2020.

BRASIL. Ministério da Educação. Programa Nacional das Escolas Cívico-Militares: o programa. Disponível em: http://escolacivicomilitar.mec.gov.br/18-o-programa. Acesso em: 14 jan. 2021.

CAETANO, M. R. O protagonismo do setor privado na reforma do Ensino Médio no Brasil - o Instituto Unibanco e suas relações. In: PERONI, V.M.V.; LIMA, P.V.; KADER, C.R. (org.) Redefinições das fronteiras entre o público e o privado: implicações para a democratização da educação. São Leopoldo: Oikos, 2018.

CAETANO, M. R. Ensino Médio e Empreendedorismo na rede estadual do Rio Grande do Sul. In: BAIRROS, M.; MARCHAND, P. (Org.). Ensino Médio: desafios e contradições. $1^{\mathrm{a}}$ ed.Porto Alegre: Cirkula, 2020, v. 1, p. 194-221.

CARVALHO, S. F. A escola não cabe numa planilha: implicações do programa jovem de futuro para a gestão democrática da educação numa escola da rede estadual do Rio Grande do Sul. Dissertação (Mestrado em Educação) - Universidade Federal do Rio Grande do Sul, 2020.

CECCHETTI, E.; TEDESCO, A. L. Educação Básica em "xeque": Homeschooling e fundamentalismo religioso em tempos de neoconservadorismo. Práxis Educativa, Ponta Grossa, v. 15, p. 1-17, 2020.

COAN, M. Educação para o empreendedorismo como estratégia para formar um trabalhador de novo tipo. Revista Labor, v. 1, n. 9, 2013, p. 1-18.

CONSELHO NACIONAL DE SECRETÁRIOS DE EDUCAÇÃO. Parceiros. Disponível em: http://www.consed.org.br/parceiros. Acesso em: 4 jan. 2021. 


\section{JORNAL DE} Políticas EducacionaIS

ISSN 1981-1969

DIÁRIO DO AMAPÁ. Governo do Amapá e Sebrae se unem para capacitar alunos e professores em educação empreendedora. Diário do Amapá, 30 set. 2020. Disponível em https://www.diariodoamapa.com.br/cadernos/cidades/governo-do-amapa-esebrae-se-unem-para-capacitar-alunos-e-professores-em-educacao-empreendedora. Acesso em: 12 jan. 2021.

GIROTTO, E. Um ponto na rede: o "Escola sem Partido" no contexto da escola do pensamento único. In: A ideologia do movimento Escola sem Partido: 20 autores desmontam o discurso. Ação Educativa Assessoria, Pesquisa e Informação (Org). São Paulo: Ação Educativa, 2016.p. 69-76.

HARVEY, D. 0 Neoliberalismo: história e implicações. São Paulo: Loyola, 2008.

LACERDA, M. B. 0 novo conservadorismo brasileiro. Porto Alegre: ZOUK, 2019.

LAVAL, C.; DARDOT, P. La pesadilla que no acaba nunca. Barcelona: Gedisa, 2017.

LIMA, P. V. Escola sem sentido: Implicações da Escola sem Partido para a democratização da educação pública. Monografia (Graduação em Pedagogia) Universidade Federal do Rio Grande do Sul, 2017.

LIMA, P. V. Influências neoconservadoras na educação pública: sujeitos em relação. In: PERONI, V.M.V.; LIMA, P.V.; KADER, C.R. (org.) Redefinições das fronteiras entre o público e o privado: implicações para a democratização da educação. São Leopoldo: Oikos, 2018.

LUKÁCS, G. Introdução a uma estética marxista. Rio de Janeiro: Civilização Brasileira, 1978.

MARX, K; ENGELS, F. A ideologia alemã. São Paulo: Boitempo, 2007.

MÉSZÁROS, I. A educação para além do capital. São Paulo: Boitempo Editorial, 2008 (Mundo do Trabalho).

MIGUEL, L. F. Da "doutrinação marxista" à "ideologia de gênero" - Escola sem Partido e as leis da mordaça no parlamento brasileiro. Revista Direito e Práxis, V. 07, n.15, p. 590-621, 2016.

MOLL NETO, R. Reaganation: a nação e o nacionalismo (neo) conservador nos Estados Unidos (1981-1988). 2010. Dissertação (Mestrado em História) - Programa de PósGraduação em História, Universidade Federal Fluminense, Niterói, 2010. 


\section{JORNAL DE Políticas EducacionaIS \\ ISSN 1981-1969}

PARAÍBA. Assembleia Legislativa. Projeto de Lei no 956/2019. Institui a Política Estadual de Educação Empreendedora, a ser desenvolvida nas escolas técnicas e de nível médio no Estado da Paraíba.

PARANÁ. Lei no 20.338/2020. Institui o Programa Colégios Cívico-Militares no Estado do Paraná e dá outras providências.

PERONI, V.M.V. A construção do Sistema Nacional de Educação e a gestão democrática em debate. In: ALMEIDA, Luana Costa et al. (Org.). PNE em foco: políticas de responsabilização, regime de colaboração e Sistema Nacional de Educação. Campinas: Cedes, 2013. P. 1021-1033.

PERONI, V. M. V.; CAETANO, M. R.; ARELARO, L. R. G. BNCC: disputa pela qualidade ou submissão da educação? Revista Brasileira de Política e Administração da Educação, v. 35, p. 035-056, 2019.

PERONI, V. M. V.; CAETANO, M. R.; LIMA, P. V. Reformas educacionais de hoje: as implicações para a democracia. Retratos da Escola, v. 11, n. 21, p. 415-432, jul/dez 2017.

PERONI, V. M. V.; LIMA, P. V. Políticas conservadoras e gerencialismo. Práxis Educativa (UEPG. ONLINE), v. 15, p. 1-20, 2020.

PERONI, V. M. V. Relação público-privado no contexto de neoconservadorismo no Brasil. Educ. Soc., Campinas, v. 41, e241697, 2020.

PERONI, V. M. V.; OLIVEIRA, C. M. B. O curso Gestão para Aprendizagem da Fundação Lemann como processo de institucionalização do gerencialismo nas escolas de educação básica alagoanas: implicações para a democratização da educação. Educ. rev., Curitiba, v. 36, e77554, 2020.

PICOLI, B. A. Homeschooling e os irrenunciáveis perigos da educação: reflexões sobre as possibilidades de educação sem escola no mundo plural a partir de Arendt, Biesta e Savater. Práxis Educativa, Ponta Grossa, v. 15, e2014535, p. 1-22, 2020.

PUELLO-SOCARRÁS, J. F. Nueva gramática del Nel-liberalismo: Itinerarios teoricos, trayectorias intelectuales, claves ideologicas. Bogotá: Universidad Nacional de Colombia, Facultad de Derecho, Ciencias Políticas y Sociales, 2008.

RIKOWSKI, G. Privatização em educação e formas de mercadoria. Retratos da Escola, Brasília, v. 11, n. 21, p. 393-413, jul./dez. 2017. 


\section{JORNAL DE}

\section{Políticas EducacionaIS \\ ISSN 1981-1969}

RIO GRANDE DO SUL. Lei 15.410 de 19 de dezembro de 2019. Institui a Política Estadual de Educação Empreendedora, a ser desenvolvida no âmbito das escolas técnicas e das escolas de nível médio do Estado do Rio Grande do Sul. Porto Alegre, 2019.

ROSSI, A.J. As políticas de diversidade na educação: uma análise dos documentos finais das CONAEs, DCNs e PNE. 2016. Tese (Doutorado em Educação) - Universidade Federal do Rio Grande do Sul, 2016.

SEBRAE. Histórico e perfil: quem somos. Disponível em:

https://www.sebrae.com.br/sites/PortalSebrae/ufs/rs/quem somos?codUf=22. Acesso em: 14 jan. 2021.

THOMPSON, E. P. A Miséria da Teoria ou um Planetário de Erros. Rio de Janeiro: Zahar, 1981.

WENDLER, J. M.; FLACH, S. F. Reflexões sobre a proposta de Educação Domiciliar no Brasil: o Projeto de Lei № 2401/2019. Práxis Educativa, Ponta Grossa, v. 15, e2014881, p. 1-13, 2020. 


\section{JORNAL DE PoLíticas EducacionaIS Volume 15 Número 36 \\ 26 de agosto de 2021}

(c)

SORERTGHISRESERVED O Copyright é retido pelo/a autor/a (ou primeiro co-autor) que outorga o direito da primeira publicação ao Jornal de Políticas Educacionais. Mais informação da licença de Creative Commons encontram-se em https://creativecommons.org/licenses/by-nc-nd/4.0. Qualquer outro uso deve ser aprovado em conjunto pelo/s autor/es e pelo periódico.

JoRnal DE PolíTICAS EdUCACIONAIS é uma publicação do Núcleo de Políticas Educacionais do Setor de Educação da Universidade Federal do Paraná - NuPE/UFPR, em consórcio com a Linha de Pesquisa em Políticas Educacionais do Programa de Pós-Graduação em Educação - PPGE/UFPR, que aceita colaboração, reservando-se o direito de publicar ou não o material espontaneamente enviado à redação. As colaborações devem ser enviadas ao NuPE/UFPR, conforme orientações contidas nas páginas do periódico na internet: http://revistas.ufpr.br/jpe.

\section{INDEXAÇÃO:}

BASE DE DADOS
Sumário.Org
Google Scholar
BASE
Dimensions
Miar

DIRETÓRIOS
Scielo Educ@
Diadorim
DOAJ
Erih Plus
Latindex
EZB
ROAD
Journal 4-free

\author{
ÍNDICES \\ Index Copernicus \\ Cite Factor \\ PORTAIS \\ LiVre \\ Capes \\ Science Open \\ World Wide Science
}

(Periódico integralmente disponível apenas em via eletrônica)

Jornal de Políticas Educacionais / Núcleo de Políticas Educacionais da Universidade Federal do Paraná -

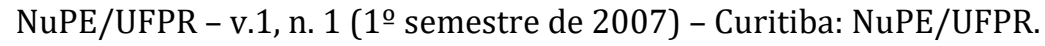

Volume 15, número 36 - Agosto de 2021

ISSN 1981-1969

1. Educação - Periódicos. 2. Política Educacional - Periódicos. I. NuPE/UFPR 


\section{JORNAL DE Políticas EducacionaIS}

Comitê Editorial:

Elisângela Scaff (UFPR)

Daniela de Oliveira Pires (UFPR)

Conselho Editorial:

Adriana Aparecida Dragone Silveira (UFPR-Brasil), Ana Lorena de Oliveira Bruel (UFPR-Brasil), Andréa Barbosa Gouveia (UFPR - Brasil), Angela Maria Martins (FCC, Brasil), Angelo Ricardo de Souza (UFPRBrasil), Antonia Almeida Silva (UEFS, Brasil), Cassia Alessandra Domiciano (UFPR-Brasil), Cesar Tello (Universidad Nacional Tres Febrero, Argentina), Claudia Regina Baukat Silveira Moreira (UFPR-Brasil), Cristiane Machado (Unicamp- Brasil), Elton Luiz Nardi (UNOESC, Brasil), Fernanda Saforcada (Universidad de Buenos Aires - UBA - Argentina), Isaac Paxe (Instituto Superior de Ciências da Educação (ISCED- Luanda, Angola), Gabriela Schneider (UFPR-Brasil), Gladys Beatriz Barreyro (USP - Brasil), Gilda Cardoso Araújo (UFES - Brasil), Gustavo Enrique Fischman (Arizona State University - USA), Janete Maria Lins de Azevedo (UFPE, Brasil), Jefferson Mainardes (UEPG - Brasil), João Ferreira de Oliveira (UFG - Brasil), Jorge Alarcon Leiva (Universidad de Talca - Chile), Jorge Manuel Gorostiaga (UNSAM - Argentina), Juca Gil (UFRGS Brasil), Luciana Rosa Marques (UFPE, Brasil), Marcos Alexandre dos Santos Ferraz (UFPR-Brasil) Marcia Aparecida Jacomini (Unifesp-Brasil), Maria Dilnéia Espíndola Fernandes (UFMS, Brasil), Natalia Oliveira Woolley (UCLA, USA), Ney Cristina Monteiro de Oliveira (UFPA - Brasil), Nicolás Bentancur, (Universidad de la República de Uruguay), Nora Krawczyk (Unicamp- Brasil), Pedro Flores-Crespo (UAQ, México) Rodrigo da Silva Pereira (UFBA, Brasil), Robert Verhine (UFBA - Brasil), Rosana Cruz (UFPI - Brasil), Rubens Barbosa Camargo (USP - Brasil), Sebastián Donoso Díaz (Universidad de Talca - Chile), Theresa Adrião (UNICAMP Brasil), Vera Maria Vidal Peroni (UFRGS - Brasil).

Créditos e Agradecimentos:

Revisão de Língua Portuguesa, Abstract e Resumen: Programa de apoio às publicações científicas periódicas da UFPR

Arte e diagramação: Tiago Tavares (tiagotav@gmail.com)

Jornal de Políticas Educacionais

Universidade Federal do Paraná

Setor de Educação

Núcleo de Políticas Educacionais - NuPE/UFPR

Avenida Sete de Setembro, 2645

$2^{\circ}$ andar, Sala 213

80.230-010 - Curitiba - PR - Brasil

Tel.: 41-3535-6264

jpe@ufpr.br

http://revistas.ufpr.br/jpe 